\title{
Fodor, Mónika. 2020. Ethnic Subjectivity in Intergenerational Memory Narratives: Politics of the Untold. New York and London: Routledge. 285 pp.
}

\section{Reviewed by Izabella Agárdi, iASK izabella.agardi@iask.hu}

Mónika Fodor's Ethnic Subjectivity in Intergenerational Memory Narratives is a theoretically dense, impeccably researched and well-written study of the personal narratives that second and later generations of Americans of mostly Central-European origin tell and retell about their ethnic backgrounds. Based on empirical research carried out over the past twenty years, the source material in this study consists of fifty-one interviews, some carried out in personal meetings and some online. Although Fodor broadly defines her informants as "European-American," the majority of the seventeen interviewees whose texts are analyzed in this work have a Hungarian or mixed Central-European ethnic background (e.g., GermanHungarian, Croatian-Hungarian), and their stories bear crucial historical and cultural imprints of the multiethnic and multilingual communities of the former Austro-Hungarian Empire. One interviewee is of German origin, one of Italian and two interviewees are of Hungarian and Irish/Scottish or "other European" descent. We do not get much information about the descendants' age but based on the detailed table of interviewees provided on page 4, we learn that in some cases the interviews were recorded over a span of fifteen years, which probably means different life phases for the informants. The personal accounts Fodor picks for her analyses are undoubtedly those of mature people with rich life-experiences at their base and with a developed sense of self and enhanced level of self-reflection.

The informants are mostly second or third generation descendants of families that ane point decided to leave their home countries and try to create for themselves a better life in the United States. Some of the families left Europe as early as the mid-nineteenth century, following the wave of the 1848 European revolutions; some left at the turn of the nineteenth and twentieth century as part of the great first wave of westward immigration and decided to stay in the U.S after the 1924 immigration law, and others tried to seek a more secure and peaceful life after the Second World War, or during or following the Hungarian Revolution of 1956. These personal accounts all share the common feature of postmemory, meaning fragmented "inherited memories," many of them traumatic, which the narrators might have heard from others but not experienced themselves. As the author so eloquently puts it, "[t]hese are the narratives that lie unassembled in the deep drawers of archives, scattered through church records, or have long been forgotten as full-fledged personal memories filtered from the life events of deceased family members" (3). 
Armed with Katherine Kohl Riessman's methodology of narrative analysis (divided into the three concepts of content, structure and performance), and with the Labovian typology of units of plot and meaning, Fodor embarks on a journey into the practices by which individuals ascribe meaning to their ethnic identities and identifications as members of a "heterolocal discourse community," as we may read in the summary of the volume (iv). In my understanding Fodor's researched community consists of individuals who are geographically scattered yet have similar ways of identifications as Americans of different European ethnic origins. Fodor's narrative analyses are divided into five themes that are highlighted in the book's five chapters, following an Introduction and a first chapter that lays the theoretical basis for the later discussions. These themes are: the discursive construction of ethnic selves, patterns of assimilation, the emergence of historical consciousness, memories as sites of ethnic subjectivity, and finally traditions as enactments of ethnicity for Americans of Central-European descent.

After a brief yet very informative introduction to the volume, Chapter 1 lays the theoretical foundations for Fodor's approach to personal intergenerational memory narratives. Here the author effectively connects current critical theories of ethnicity and assimilation to wellestablished study approaches to memory, narrative and subjectivity construction. The distinction between identity and subjectivity is a rare albeit welcome component of Fodor's complex theoretical frame, as it creates an especially fertile ground, where individuals' embeddedness in social, cultural and political discourses acquires meaning while also leaving space for theorizing issues such as interpretive agency or pondering one's "victimcy" meaning their sense of victimhood. Chapter 2, titled "I just Feel Unique," zooms in on the first theme, namely the discursive construction of the ethnic self. In this chapter the reader encounters the ambiguous attitude of second and later generations descendants of mostly Central-Europeans to their ethnic heritage, and their enormous lack of information regarding the actual lives of their ancestors. The author sensitively shows how all of the narrators grapple with the question of how to fit their inherited stories into their lives so that these stories remain meaningful for them. Richard's story about his parents' denial of their ethnicity, or Rosemaria's gendered memories about her traumatic experiences with her father, are examples of disconnection to and rejection of ethnocultural heritage. By contrast, the stories told by Steve and Jason certainly attribute social and cultural value to ethnicity through the stories of their respective ancestors. Both these narrators relate stories that feature courage, perseverance (Steve) and successful acculturation (Jason) as necessary traits that have shaped the narrators' own views on life. Following the generic conventions of personal oral narratives, the practices of justifying one's agency through the ancestors' stories and assuming responsibility for knowing one's past are all important common elements of most if not all the accounts in this chapter.

Chapter 3, "My Style of Being Ethnic," examines the theme of assimilation in the narratives, focusing on the recurrent elements or motifs that build up these stories, and the value of such an approach for the nuanced conceptualization of assimilation in American society today. The stories in this chapter sound a bit more detailed and full of action than those of the previous one and they tell the experiences of how the narrators' ancestors transitioned into the new country, managing to adapt to their new circumstances, and how their descendants have managed to create lives in two communities. Of special interest are the ways in which descendants connect some of their parents' experiences to their own macro-social context or macro-historical turning points. Matthew's story about his father's farm having been burned down by the Ku Klux Klan in the 1920s is one of the most graphic and dense inherited memories that we encounter in this chapter. Issues of gaining or losing social capital by investment in one's ethnic heritage, or the 
difficulties of grappling with liminality, make this chapter especially illuminating. Furthermore, Fodor's discussion of intermarriages as long-lasting platforms of ethnic-identity negotiations, although possibly deserving a separate chapter, shows another facet of ethnicity that connects to debates on ethnicity and its gendered dimensions.

Chapter 4, "History Got in the Way," is about the descendants' inherited memories of historical trauma and persecution, and it features their stories about all the larger historical circumstances of wars, forced-labor camps, revolutions, economic adversities or political persecution, which influenced the ancestors' decision to leave their home countries. Leaving as a way of survival, because suddenly one finds oneself on the wrong side of history, is discussed in varied ways through many different memory accounts in which the informants deal with both the powerlessness and fragility of the protagonists of their stories and their own difficulties when trying to interpret their actions amidst a shocking lack of information and heavy silences. Paul's and John's stories about their respective fathers' active or passive role in the Second World War (one father was a state employee and the other an army official), for instance, open the stage for the sensitive question of historical responsibility, and the discrepancies that lie in the assessments of one's parent as both a private person and as a historical subject. Other stories, like the one about Jason's father, who spent years in a Soviet Gulag, or of Steve's father, who was persecuted for his role in the 1956 Hungarian Revolution, each tell different albeit often-told family narratives of political victimhood, which in retrospect have gained historical legitimacy. The performativity of oral-history narratives, achieved by a joint creation of meaning by the narrators and their real and imagined audiences (also termed "intersubjectivity" of knowledge production in the scholarly literature) becomes immensely significant here as it highlights the difference between formal-historical, linear narratives and complex, non-linear oral-history accounts.

Chapter 5, "At Home There," treats another theme that emerged as common for several narratives. As the title of this chapter shows, it discusses stories about people's real or imagined places of belonging. Stories about one's family express emotional attachment to places (and time periods) that function as meaningful sites of (post)memory in these family stories, and also as sites of ethnic identification. In the section sub-titled "Roots trips" in this chapter we come upon interesting, albeit rather familiar, stories about visiting the "homeland" and encountering a reality that has become quite different from the narrator's remembered or imagined place of belonging. Adam's story about his "accidental" even if historically decisive role in returning the Holy Crown to the Hungarian State also reads rather familiar. This is so because many people who worked at the Hungarian administration or foreign-affairs offices in the late 1970s likewise claim to have had a role in this noble act by the Carter administration. Adam's subsequent visit to Hungary in 1983, however, turns out to be a disappointment, and his story about this visit depicts a bleak country with embittered, misled people. In general, the stories in this chapter are emotionally charged and rather fragmented, thus justifying the narrators' sense of "impossibility of return" (237).

The book's sixth and final chapter focuses on issues of tradition, as it is also a central theme in the memory narratives of second and third generation European-Americans. The narrators' mundane everyday lives are framed by an intricate web of traditions from different ethnocultural backgrounds. In these stories Eric Hobsbawm's concept of "invented tradition" is turned by the informants into an enacted tradition, i.e., a tradition that exists very much in practice and in the discourse about praxis. This chapter shows us how traditions emerge through stories about food culture and culinary nostalgia, as well as about recreating certain celebration rituals of Christian Holidays or performing the tradition of balls or dances. The chapter cites 
stories by exclusively female narrators, which confirms the gendered nature of the transmission of tradition and old customs, as well as the ways in which that they inform mostly female ethnic subjectivities.

As mentioned above, Fodor discusses intergenerational memory-narratives under the wide and diverse category of "European-American." Such a categorization is of course geographically valid and conveniently positions the work for an international reading audience. Reading it from a situated Central-European perspective (if there exists one such perspective), however, the category of "European-American" seems somewhat vague and depriving the stories of some of their regional and historical specificity. The cultural production of ethnicity through shared meanings and attached values rarely occurs in a void. Rather, people's sense of history (of both their home and their host countries) and their macrosocial contexts change in tandem. Knowing the different ways in which ancestors from different countries created different life trajectories, the question arises if descendants with historically contested and vastly burdened backgrounds can all be discussed under the same criteria and umbrella category of "European." Having said that, by no means do I propose to formulate a separate category based on various intra-European geo-political settings. However, the reader does get a sense that out of all the European ethnicities featured in this book, the author's main concern are the discursive negotiations of being Hungarian and the immense sense of liminality of being form the other part of Europe, somewhere between East and West. Addressing this issue more deeply could perhaps open up further horizons for a much-needed continuation of scholarly dialogue on the diversity of ethno-historical heritage, identity and memory work aimed at facing imperial pasts, and even the far-reaching legacy of the First World War.

Throughout the study, the author demonstrates her profound interest and commitment to foreground individual voices. She derives her theoretical insights based on the stories, which ultimately end up refining our existing theories on processes of assimilation and the formation of ethnic subjectivities. Although a contextualization in other diasporic literatures would have been welcome in some of the comparative analyses of her study, Fodor's sophisticated theoretical language and methodological rigour make this book a must for anyone studying the creation of personal stories in general and of the formulations of personal ethnicity in the U.S context in particular. Apart from the highly technical analytical sections, which are a real treat for scholars of narrative and memory, anyone who is interested in stories of individuals of Hungarian or Central-European descent and the ways in which they negotiate their ethnocultural heritage would find in this book fascinating and often moving discussions. The deeper messages of Mónika Fodor's work are also of relevance in other present-day social contexts. Since ethnicity is one of the crucial elements forming our sense of who we are, and one which determines our positioning in society, the study of individuals' dynamic relations with their ethnicity is relevant in European nation-states just as much as elsewhere. Fodor asks the questions that many of us are interested in, but hardly ever end up asking, namely how our family roots that have been framed by told and untold family stories, myths and silences inform our sense of who we are and where we think and feel we belong. In this sense, Fodor's work has a pivotal place in critical minority studies, ethnographies of transnational families and diasporic communities and studies of cultural citizenship. 